\title{
KONSERVASI ENERGI LISTRIK PADA BANGUNAN GEDUNG KANTOR BUPATI TOJO UNA-UNA
}

\author{
Jordan A. Tiro ${ }^{1}$, Baso Mukhlis ${ }^{2}$, Agustinus Kali ${ }^{3}$, Maryantho $\mathbf{M}^{4}$, Irwan Mahmudi ${ }^{5}$ \\ Fakultas Teknik, Jurusan Teknik Elektro, Universitas Tadulako \\ 2,3,4,5) Dosen Teknik Elektro Universitas Tadulako \\ email: panelarester@gmail.com
}

\begin{abstract}
Electrical energy has a very important role in the economic, industrial and social development of the community, this causes an increase in the demand for electrical energy in line with the increase in people's welfare, economic and industrial growth. On the other side, energy sources that are commonly used for power generation are increasingly expensive and limited in availability and cause environmental pollution. Based on these considerations, it is necessary to implement an energy management program to preserve energy resources and use energy effectively. Energy consumption intensity (ECI) is a term used to determine the amount of electrical energy consumption in a room. The calculation of the intensity of energy consumption carried out at the Tojo Una-una regent's office in Central Sulawesi consists of 3 buildings with 129 rooms, it was found that 7 rooms were categorized as quite efficient and wasteful.
\end{abstract}

Keywords : Conservation of electrical energy, Audit of electrical energy, Efficienci of electrical energy, Energy consumption intensity, Energy saving opportunities, Regent's office of Tojo Unauna

\section{Pendahuluan}

\subsection{Latar Belakang}

Energi listrik mempunyai peranan yang sangat penting dalam pembangunan ekonomi, industri dan sosial masyarakat, hal ini menyebabkan terjadinya peningkatan permintaan energi listrik seiring dengan peningkatan kesejahteraan masyarakat, pertumbuhan ekonomi dan industri. Disisi lain, sumber-sumber energi yang umum digunakan untuk pembangkit listrik, semakin mahal dan ketersediaanya terbatas serta menimbulkan pencemaran lingkungan. Berdasarkan pertimbangan tersebut, perlu dilaksanakan program manajemen energi untuk menjaga kelestarian sumber daya energi dan pemanfaatan energi yang efektif.

Perkembangan perekonomian yang terjadi di segala sektor menyebabkan pembangunan gedung-gedung semakin pesat, termasuk pembangunan Gedung perkantoran. Peran energi listrik tentunya sangat besar dalam hal ini. Salah satu perkantoran yang senantiasa mengalami perbaikan fungsi yaitu kantor bupati. Dalam kegiatan operasionalnya mengharuskan ketersediaan energi listrik yang terus menerus atau kontinyu. Penggunaan energi listrik di kantor yang cukup besar dapat kita lihat seperti ,Air Conditioning (AC), lampu Pencahayaan, komputer, dan peralatan kantor lainnya. [1]

Salah satu upaya nyata untuk menghemat energi listrik yaitu dengan peningkatan efisiensi penggunaan energi listrik secara efisien dan bijaksana. Hal ini tertuang dalam instruksi Presiden (INPRES) No.13 tahun 2011 tentang Penghematan Energi dan Air dan Peraturan Pemerintah (PP) (Tentang Konservasi Energi). Meningkatkan efisiensi energi telah diyakini sebagai salah satu cara efektif untuk menambah keuntungan usaha dimana biaya yang dikeluarkan untuk pembelian energi menjadi berkurang. Saat ini istilah penghematan ini 
dikenal dengan konservasi energi, yang merupakan penggunaan energi dengan efisiensi dan rasional tanpa mengurangi penggunaan energi yang memang benar-benar diperlukan. Upaya konservasi energi ini diterapkan pada seluruh tahap pemanfaatan, mulai dari pemanfaatan sumber daya energi sampai pada pemanfaatan akhir, dengan menggunakan teknologi yang efisien, dan membudayakan pola hidup hemat energi. Hal ini tentunya juga sangat perlu diterapkan di kantor untuk mendukung ketersediaan energi listrik yang kontinyu namun biaya yang dikeluarkan juga tidak begitu besar. [2]

\subsection{Tujuan}

Untuk meningkatkan efisiensi energi listrik dan mengurangi penggunaan energi listrik yang tidak perlu agar mengurangi biaya pemakaian energi listrik.

\section{Landasan Teori}

\subsection{Tinjauan Pustaka}

Penelitian yang dilakukan oleh Suhendar, Ervan Efendi, dan Herudin (2013), yang berjudul "Audit Sistem Pencahayaan dan Sistem Pendingin Ruangan di Gedung Rumah Sakit Umum Daerah (RSUD) Ciligon“ menunjukkan hasil bahwa terjadi kenaikan total pemakaian konsumsi energi listrik dari tahun 2010-2012 masing-masing sebesar 1.095.142 kWh/tahun, 1.426.199 kWh/tahun, dan 1.650 .398 $\mathrm{kWh} /$ tahun. Tahapan yang dilakukan peneliti diawali dengan melakukan audit awal dengan menghitung Intensitas Konsumsi Energi (IKE). Setelah melalui proses perhitungan penghematan konsumsi energi listrik untuk perbaikan pencahayaan yaitu sebesar $64,07 \%$, penghematan konsumsi energi listrik pada pendingin ruangan dengan pergantian freon musicool. Penghematan konsumsi listrik setelah penggantian jenis AC Inverter sebesar 19,6\%. Hasil penelitiannya dilakukan dengan cara mengantikan lampu penerangan dengan jenis LED dan untuk pendingin ruangan digantikan dengan $\mathrm{AC}$ jenis AC Inverter. [3]

\subsection{Klasifikasi Audit Energi}

1. Survei Energi (Energy Survey or Walk Through Audit) Sering disebut mini audit. Audit yang dilakukan secara sederhana, tanpa penghitungan yang rinci, hanya melakukan analisa sederhana. Umumnya fokus dari audit ini adalah pada bidang perawatan dan penghematan yang tidak memerlukan biaya investasi yang besar. Biasanya auditor bukan seseorang yang profesional dalam bidang audit energi.

2. Audit Energi Awal (Preliminary Energy Audit) Tujuan dari audit energi awal adalah untuk mengukur produktifitas dan efisiensi penggunaan energi dan mengidentifikasi kemungkinan penghematan energi .Kegiatan audit energi awal meliputi identifikasi gedung, analisa kondisi aktual, menghitung konsumsi energi, menghitung pemborosan energi, dan beberapa usulan.

3. Audit Energi Rinci (Detailed Energy Audit or Full Audit) Audit energi rinci adalah audit energi yang dilakukan dengan menggunakan alat-alat ukur yang sengaja dipasang pada $p$ eralatan untuk mengetahui besarnya konsumsi energi. Biasanya dilakukan oleh lembaga auditor yang profesional dalam jangka waktu tertentu. Pelaksanaan audit didahului dengan analisa biaya audit energi, identifikasi gedung, analisa kondisi aktual, dan menghitung semua konsumsi energi. Konsumsi energi ini meliputi energi primer, seperti listrik dan bahan bakar, juga energi sekunder; seperti air, telepon, dan lain-lain. Selain itu, melakukan penghitungan pemborosan energi, kesempatan konservasi energi, sampai beberapa usulan untuk melakukan penghematan energi beserta dengan analisa dampak usulan tersebut [4]

\subsection{Intensitas konsumsi Energi}




\section{Intensitas Konsumsi lenergi (IKE)} merupakan istilah yang digunakan untuk mengetahui besarnya pemakaian energi listrik dalam bangunan Gedung dan dinyatakan dalam satuan $\mathrm{kWh} / \mathrm{m}^{2}$. Hasil nilai IKE harus sama atau lebih kecil dari nilai standar dan selalu diupayakan untuk dipertahankan lebih rendah.

Menurut pedoman pelaksanaan konservasi energi listrik dan dalam menentukan prestasi penghematan energi. Untuk gedung kantor dan bangunan gedung komersial dapat mengacu kepada standar nilai IKE yang diperlihatkan sebagai berikut:

$>$ Untuk Gedung Ber-AC :

- $\quad$ Sangat efisien $=(\operatorname{IKE}<8,5) \mathrm{kWh} / \mathrm{m} 2$ /bulan,

- Efisien $=(8,5 \leq \mathrm{IKE}<14) \mathrm{kWh} / \mathrm{m} 2$ /bulan,

- Cukup efisien $=(14 \leq \mathrm{IKE}<18,5)$ $\mathrm{kWh} / \mathrm{m} 2$ /bulan,

- Boros $=(\mathrm{IKE} \geq 18,5) \mathrm{kWh} / \mathrm{m} 2 / \mathrm{bulan}$, Untuk Gedung Tidak Ber-AC :

- $\quad$ Sangat efisien $=(\operatorname{IKE}<3,4) \mathrm{kWh} / \mathrm{m} 2$ /bulan,

- Efisien $=(3,4 \leq \mathrm{IKE}<5,6) \mathrm{kWh} / \mathrm{m} 2$ /bulan,

- Cukup efisien $=(5,6 \leq \mathrm{IKE}<7,4)$ $\mathrm{kWh} / \mathrm{m} 2$ /bulan,

- Boros $=(\mathrm{IKE} \geq 7,4) \mathrm{kWh} / \mathrm{m} 2 /$ bulan. [5]

\subsection{Peluang hemat energi}

Besarnya IKE hasil perhitungan dibandingkan dengan IKE standar. Bila hasilnya ternyata kurang dari IKE standar maka kegiatan audit rinci dapat dihentikan atau bila diteruskan dengan harapan dapat memperoleh IKE yang lebih rendah lagi. Bila hasilnya lebih dari IKE target, berarti ada peluang untuk melanjutkan proses audit energi rinci. [6]

\section{Metode Penelitian}

Untuk mencapai tujuan dari penelitian ini, metodologi yang digunakan berupa metode observasi langsung melakukan pengukuran luas ruangan dan mendata seluruh jumlah peralatan listrik yang ada pada suatu rungan di samping membagikan format pengisian data peralatan pada setiap ruangan. Setelah data-data peralatan seperti jumlah dan daya peralatan yang digunakan seperti data ac, jenis lampu penerangan, televisi, komputer, dispenser, dan peralatan lainnya yang digunakan serta lama waktu pengoperasian peralatan, lalu dilakukan perhitungan untuk menentukan nilai IKE ruangan

\section{Hasil dan Pembasan}

Audit energi merupakan salah satu cara yang dapat dilakukan untuk mengevaluasi penggunaan energi. Audit energi akhir-akhir ini telah banyak dilakukan di industri maupun bangunan komersial sebagai kegiatan untuk mengetahui dan mengevaluasi potensi penghematan energi pada suatu fasilitas atau sistem energi. Berbagai kegiatan dilakukan dalam audit energi mulai dari pengumpulan data, pengukuran dan pengamatan lapangan, analisis data serta penyusunan laporan. Penyusunan laporan merupakan bagian kecil dari keseluruhan audit energi, namun kegiatan ini menjadi penting karena merupakan jembatan dalam menyampaikan hasil dari keseluruhan audit energi ke pimpinan organisasi yang akan mengambil keputusan atas rekomendasi yang diberikan. Sebuah program audit energi dalam rangka efisiensi energi haruslah dimulai dan mendapat dukungan dari pihak pimpinan. Artinya pimpinan harus memahami dengan jelas konsep analisa cost-benefit dari sebuah program efisiensi energi. Masukan dan saran dari semua pihak sangat penting bagi suksesnya sebuah program efisiensi energi yang akan dilakukan. Target penghematan yang akan dicapai harus dituangkan ke dalam suatu rencana aksi yang disusun bersama. Dalam menerapkan rencana aksi tersebut, proses monitoring yang rutin harus dilakukan. Setelah 
masa implementasi selesai, harus dilakukan evaluasi untuk mengetahui apakah target penghematan sudah tercapai ataukah belum.

\subsection{Ruangan dan peralatan listrik}

Dari pengambilan data dan penelitian konservasi energi listrik di kantor bupati tojo una-una. Sumber energi yang digunakan kantor bupati tojo una-una dalam menjalankan pelayanan kepada masyarakat adalah energi listrik dari PLN dengan kapasitas trafo 200KVA dengan daya tersambung $165 \mathrm{KV}$ serta memiliki cadangan sumber listrik apabila PLN padam yaitu genset dengan kapasitas 60KVA, 48kW. Adapun data jenis peralatan, jenis peralatan, daya dari setiap jenis peralatan serta luas dari setiap ruangan yang ditempati oleh peralatan yang tidak dapat penulis tampilkan secara detail mengingat jumlah ruangan yang banyak lebih dari 100 ruangan yang jika ditampilkan akan menempati beberapa halaman penulisan. Namun untuk memperlihatkan data-data yang dapat digunakan sebagai contoh dalam menghitung nilai intensitas konsumsi energi dan peluang penghematannya maka pada tabel di bawah ini diperlihatkan beberapa ruangan saja dari beberapa ruangan yang ada di kantor bupati Tojo Una-una.

Tabel 1. Jenis peralatan dan luas ruangan

\begin{tabular}{|c|c|c|c|c|c|c|c|c|c|c|c|c|c|c|c|c|c|c|c|}
\hline \multirow{4}{*}{ Ilema Rusaggan } & \multirow{4}{*}{$\begin{array}{c}\text { Luas } \\
\text { RuAGGA } \\
\text { N(m2) }\end{array}$} & \multicolumn{18}{|c|}{ PESLLTAN } \\
\hline & & \multicolumn{4}{|c|}{ Lampo } & \multicolumn{4}{|c|}{ AL } & \multirow{2}{*}{\multicolumn{2}{|c|}{ N }} & \multirow{2}{*}{\multicolumn{2}{|c|}{ Laplep }} & \multirow{2}{*}{\multicolumn{2}{|c|}{ Depenger }} & \multirow{2}{*}{\multicolumn{2}{|c|}{ xc }} & \multirow{2}{*}{\multicolumn{2}{|c|}{ Printer }} \\
\hline & & \multicolumn{2}{|c|}{8} & \multicolumn{2}{|c|}{$\pi$} & \multicolumn{2}{|c|}{$10 \mathrm{k}$} & \multicolumn{2}{|c|}{$28 R$} & & & & & & & & & & \\
\hline & & Jumba & Dala & Jumbh & DF & Jumbh & Dala & Jumlah & $D z \beta$ & Jumlah & $\mathrm{Da} / \mathrm{a}$ & Jumlah & Dep & Jumlah & Dapa & Jumbh & D283 & Jumlah & Dala \\
\hline 1 R.uPP:1 & 80 & 1 & 27 & $\cdot$ & $\cdot$ & . & $\cdot$ & 2 & 1990 & 1 & 75 & 11 & 65 & 1 & 420 & . & $\cdot$ & . & . \\
\hline 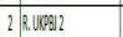 & 40 & 1 & 32 & . & . & 1 & 800 & . & $\cdot$ & . & . & 3 & 65 & . & . & . & . & 1 & 10 \\
\hline 3 R.UPed 3 & 40 & 2 & 27 & . & . & . & . & 1 & 1980 & . & . & . & . & . & . & 1 & 200 & 1 & 10 \\
\hline 4 R.UPe 4 & 80 & 7 & 27 & . & . &. & . & 3 & 1980 & 1 & 134 &. &. & 1 & 420 & 11 & 200 & 5 & 10 \\
\hline 5 R.begiankan. & 120 & 6 & 27 & 6 & 40 & . & . & 3 & 1900 & 1 & 100 & 8 & 65 & 2 & 420 & 4 & 200 & 5 & 10 \\
\hline 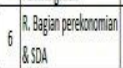 & 120 & 6 & 45 & . & . & . & . & 3 & 1980 & 1 & 134 & . & . & 1 & 300 & 4 & 230 & 4 & 10 \\
\hline 7 R. kesid & 120 & 6 & 27 & 6 & 40 & . & . & 3 & 1900 & 1 & 100 & 5 & 65 & 2 & 420 & 4 & 200 & 5 & 10 \\
\hline 8 R.Gudang 1 & 20 & $\cdot$ &. & 2 & 40 &. &. & $\cdot$ &. &. & $\cdot$ &. &. &. & . &. &. &. & . \\
\hline 9 R. Gubang 2 & 10 &. & . & 1 & 40 & . &. & . & . & . & . & . & . &. &. &. &. & . & . \\
\hline 10 WC1 & 6 & 1 & 10 & . & . & . & . & . & . &. & . &. & . & . & . & . & . & . & . \\
\hline
\end{tabular}

\subsection{Intensitas Konsumsi Energi (IKE)}

Intensitas konsumsi energi diartikan sebagai perbandingan antara jumlah pemakaian energi listrik per bulan atau per tahun dengan luas ruangan atau bangunan (kwh/m2 perbulan atau pertahun). Data-data yang diperlihatkan pada tabel 1 di atas hanya merupakan data-data ruangan yang diambil sebagai sampel dalam menghitung Intensitas Konsumsi Energi dari setiap ruangan.

Menurut Agus Maulana dkk.. 2005 intensitas konsumsi energi per tipe ruangan dapat dihitung dengan menggunakan persamaan berikut:

$$
=\frac{\mathrm{kWh} \text { Total }}{\text { Luas Ruangan }\left(\mathrm{m}^{2}\right)}(\mathrm{kwh} / \mathrm{m} 2)
$$

Untuk menghitung nilai intensitas konsumsi energi (IKE) dari setiap ruangan pada penelitian ini digunakan asumsi sebagai berikut:
a. AC 2 PK $=1672$ watt
b. printer $=10$ watt
c. televisi $=134$ watt
d. Komputer $=230$ watt
e. Dispenser $=300$ watt

Waktu operasi peralatan dirata- ratakan 8 jam setiap hari, selama 22 hari kerja dalam sebulan.

Untuk menghitung perkiraan besarnya konsumsi energi dari peralatan yang ada di setiap ruangan digunakan persamaan:

\section{Konsumsi listrik = Daya $(k W) \quad x$ waktu pemakaian (jam) x 22 hari}

Sebagai contoh, untuk menghitung nilai IKE dari salah satu ruangan yang ada di fakultas Teknik Untad dilakukan dengan cara sebagai berikut:

- Nama ruangan $=$ Ruang UKPBJ 4

- Luas dan kategori ruangan $=80 \mathrm{~m} 2 /$ ruangan ber-AC 
- Paralatan listrik yang digunakan:

1. AC standar daya 2 PK 3 buah

2. Lampu SL 7 buah

3. Televisi 1 buah

4. Komputer 1 buah

5. Printer 5 buah

6. Dispenser 1 buah

Dari data di atas, maka jumlah daya dari setiap peralatan yang ada di dalam ruangan dekan Fakultas Teknik adalah sebagai berikut:

$>\mathrm{AC} \quad=3 \times 1672 \mathrm{watt}=5.016 \mathrm{watt}$

$>$ Lampu SL $=7 \times 27$ watt $=189$ watt

$>$ Televisi $=1 \times 134$ watt $=134$ watt

$>$ Komputer $=11 \times 230 \mathrm{watt}=2530 \mathrm{watt}$

$>$ Printer $\quad=5 \times 10$ watt $=50$ watt

$>$ Dispenser $=1 \times 300$ watt $=300 \mathrm{watt}$

Jumlah $=2.244$ watt

Total daya yang digunakan (kwh) dari semua peralatan dalam satu bulan:

$=8.219$ watt $\mathrm{x} 8$ jam $\mathrm{x} 22$ hari

$=1446,5 \mathrm{kwh} / \mathrm{bulan}$

Dari jumlah daya listrik yang digunakan pada ruangan seluas $80 \mathrm{~m} 2$, maka nilai intensitas konsumsi energinya (IKE) adalah:

$$
\mathrm{IKE}=\frac{1446,5}{80}
$$

$=18,08 \mathrm{kwh} / \mathrm{m} 2 /$ bulan

Bila hasil perhitungan IKE ini dibandingkan dengan nilai standar IKE, maka ruang UKPBJ 4 dikategorikan ke dalam ruangan yang cukup efisien menggunakan listrik.

Hasil evaluasi dari 129 ruangan yang telah dievaluasi terdapat beberapa ruangan yang ada pada setiap unit kerja yang nilai IKE-nya melebihi standar IKE kategori efisien, dalam hal ini ada yang masuk kategori cukup efisien dan boros menggunakan energi. Rincian jumlah ruangan yang dianggap melebihi kreteria standar IKE kategori efisien adalah sebagai berikut:
- Gedung A lantai $1=1$ ruangan, dari 21 jumlah ruangan

- Gedung A lantai $2=1$ ruangan, dari 26 jumlah ruangan

- Gedung B lantai $2=2$ ruangan, dari 16 jumlah ruangan

- Gedung C lantai $1=2$ ruangan, dari 18 jumlah ruangan

- Gedung C lantai $2=1$ ruangan, dari 24 jumlah ruangan

\section{Menentukan Target Efisiensi}

Untuk mengetahui potensi penghematan energi yang dapat diterapkan pada sebuah ruangan yang tidak masuk kategori efisien dalam menggunakan listrik, maka selisih nilai IKE hasil perhitungan dengan nilai IKE standar terlebih dahulu harus dihitung. Untuk menghitung peluang penghematan yang dapat diterapkan pada sebuah ruangan dapat digunakan persamaan berikut:

Potensi penghematan $=(\mathrm{IKE}$ ruangan - IKE target) $x$ luas area $x$ TDL

Tarif listrik yang digunakan untuk menghitung potensi penghematan pada penelitian ini disesuaikan dengan tarif listrik rata-rata yang berlaku untuk golongan P1 di Kantor bupati yaitu Rp 1.444. Sebagai contoh dalam perhitungan ini dipilih ruangan UKPBJ 4 yang memiliki data-data sebagai berikut:

- Nama ruangan $=$ ruaang UKPBJ 4

- Keadaan ruangan $=$ ber-AC

- Luas ruangan $=80 \mathrm{~m} 2$

- IKE ruangan $=17,97$ (hasil perhitungan $=$ cukup efisien)

- Standar IKE efisien $=13,9$

Potensi penghematan $=(18,08-13,9) \times 80$

x $1.444=\operatorname{Rp} 482.873$

Berdasarkan hasil penelitian yang telah dilakukan, maka salah satu hal yang dapat dilakukan untuk mengurangi biaya listrik di Untad adalah mengurangi nilai Intensitas Konsumsi Energi (IKE). 


\section{Kesimpulan}

Dari 129 ruangan di atas, sebanyak 7 ruangan yang tidak memenuhi standar IKE, dengan kategori 5 ruangan cukup efisien dan 2 ruangan boros.

1. Jumlah ruangan yang nilai IKE-nya masuk kategori Cukup efisien 5 dengan peluang penghematan Rp 1.592.954.

2. Jumlah ruangan yang nilai IKE-nya masuk kategori boros 2 dengan peluang penghematan Rp 1.523.37.

3. Bila peluang penghematan dari 129 ruangan diimplementasikan maka kantor bupati Tojo Una-una dapat menghemat biaya listrik sebanyak $\mathrm{Rp} 10.665 .822$ perbulan.

\section{Daftar Pustaka}

[1] Chikku Abraham, 2008. Energy Audit Of IIT Bombay Campus, Department of Energy Science and Engineering, Indian Institute Of Technology.

[2] Mohammad Riyadi. 2017. Konservasi Energi Listrik Rumah Sakit Umum Daerah Ampana Kabupaten Tojo Una-Una Sulawesi Tengah.

[3] Suhendar, Ervan Efendi, Herudin. 2013. Audit Sitem Pencahayaan dan Sistem Pendingin Ruangan di Gedung Rumah Sakit Umum Daerah (RSUD) Cilegon. Cilegon: Jurusan Teknik Elektro. Universitas Sultan Ageng Tirtayasa Cilegon.

[4] Baso Mukhlis. Evaluasi Penggunaan Listrik Pada Bangunan Gedung di Lingkungan Universitas Tadulako.Palu : Dosen Jurusan Teknik Elektro UNTAD Palu,Indonesia.

[5] Peraturan Menteri Energi dan Sumber Daya Mineral Republik Indonesia Nomor 13 Tahun 2012
[6] Potensi penghematan energi. Hasil Audit Energi 2006. Departemen /energi dan Sumber Daya Mineral 